\title{
Automatic apparatus, based upon a nickel-tube resonator, for measuring the complex shear modulus of liquids in the $\mathrm{kHz}$ range
}

\author{
M. Oosterbroek, H. A. Waterman, S. S. Wiseall, E. G. Altena, J. Mellema, \\ and G. A. M. Kip
}

With 8 figures and 4 tables

(Received February 29, 1980)

\begin{tabular}{|c|c|c|c|}
\hline \multicolumn{2}{|l|}{ Notations } & \multirow[b]{2}{*}{$p, p_{\text {rest }}$} & \multirow[b]{2}{*}{$\begin{array}{l}\text { track on screen when tube is in } \\
\text { motion and at rest (in App. B) }\end{array}$} \\
\hline$a$ & outer radius of the tube & & \\
\hline$A$ & apparatus constant & $t$ & time \\
\hline$b$ & distance to screen (in App. B) & $T_{\text {liq }}$ & moment per unit length exerted \\
\hline$B_{n}$ & $3 \mathrm{~dB}$-bandwith & & by the liquid on the tube \\
\hline$B_{\text {long }}$ & $\begin{array}{l}\text { longitudinal magnetization of } \\
\text { the tube }\end{array}$ & $\begin{array}{l}R_{L} \\
V_{\text {in }}, V_{\text {out }}\end{array}$ & $\begin{array}{l}\operatorname{Re}\left\{Z_{L}\right\} \\
\text { voltages }\end{array}$ \\
\hline$c_{0}$ & $\equiv \sqrt{G_{\mathrm{Ni}}^{\prime} \varrho_{\mathrm{Ni}}^{-1} \text { velocity of prop- }}$ & $X$ & $\operatorname{Re}\{\Gamma \ell / 6\}$ \\
\hline & $\begin{array}{l}\text { agation of torsional waves in a } \\
\text { tube without losses }\end{array}$ & $X_{L}$ & $\operatorname{Im}\left\{Z_{L}\right\}$ \\
\hline$C, C_{1}, C_{2}, C_{3}$ & constants & $\begin{array}{l}Y \\
z\end{array}$ & $\begin{array}{l}\operatorname{Im}\{\Gamma \ell / 6\} \\
\text { vertical coordin }\end{array}$ \\
\hline$d_{\text {eff }}$ & $\begin{array}{l}\text { thickness of "immobilized } \\
\text { liquid laver" }\end{array}$ & $Z$ & variation of $Y$ around $Y_{0}$ \\
\hline$f$ & frequency & $Z_{L}$ & mpedance \\
\hline$f_{n}$ & ce frequency & $\beta$ & $\begin{array}{l}\text { length of transmitting coll } \\
\text { length of receiving coil }\end{array}$ \\
\hline$F$ & $=H /(C \Gamma)$ & $\dot{\gamma}$ & rate of shear \\
\hline$G=G^{\prime}+i G^{\prime \prime}$ & complex shear modulus & $\Gamma$ & propagation constant \\
\hline$H$ & transfer function & $\delta$ & loss angle of nickel \\
\hline & $\sqrt{-1}$ & $\Delta_{f}$ & inertia correction term \\
\hline$I$ & $\begin{array}{l}\text { moment of inertia per unit } \\
\text { length }\end{array}$ & $\varepsilon_{G^{\prime}}, \varepsilon_{G^{\prime \prime}}$ & relative error in $G^{\prime}, G^{\prime \prime}$ \\
\hline$I_{p}$ & polar moment per unit length & & $\begin{array}{l}\text { Nederveen transform para- } \\
\text { meter }\end{array}$ \\
\hline$k$ & $3(2 n+1)$ & $\eta$ & viscosity, solvent viscosity \\
\hline$K$ & parameter indicating devia- & $\theta$ & torsion angle \\
\hline & $\begin{array}{l}\text { tions from "id } \\
\text { tube length }\end{array}$ & $\varrho$ & den \\
\hline$\ell$ & & $\omega$ & quency \\
\hline$L$ & $\begin{array}{l}\text { inductance of transmitting coil } \\
\text { ratio of inner and outer radii of }\end{array}$ & $\omega_{1}$ & fundamental angular \\
\hline$n$ & $\begin{array}{l}\text { ratio of inner and outer radii of } \\
\text { the tube }\end{array}$ & & \\
\hline$M_{\mathrm{el}}$ & $\begin{array}{l}\text { torsion moment caused by } \\
\text { elastic deformation of the tube }\end{array}$ & subscripts & \\
\hline$M_{\text {ext }}$ & $\begin{array}{l}\text { torsion moment exerted on the } \\
\text { tube by the liquid }\end{array}$ & $\begin{array}{l}0 \\
n\end{array}$ & $\begin{array}{l}\text { at resonance without loss terms } \\
\text { index of used overtones }\end{array}$ \\
\hline & integer & $\mathrm{Ni}$ & nickel \\
\hline V & $\begin{array}{l}\text { number of turns in receiving } \\
\text { coil }\end{array}$ & superscripts & \\
\hline D & $\begin{array}{l}\text { cross section area of receiving } \\
\text { coil }\end{array}$ & $\begin{array}{l}A \\
N\end{array}$ & $\begin{array}{l}\text { air } \\
\text { Newtonian calibr }\end{array}$ \\
\hline & & & $\mathbf{N}$ \\
\hline
\end{tabular}




\section{Introduction}

The viscoelastic behaviour of liquids in the $\mathrm{kHz}$ range has been the subject of intensive research. Special interest for the investigation of dilute polymer solutions has resulted in various methods of measuring viscoelastic behaviour in this frequency range.

The first method using a torsional crystal resonator was developed by Mason (1) and improved several times $(2,3,4,5)$. Only monocrystals can be used after careful cutting and polishing. The mechanical properties of the liquid that surrounds the crystals can be determined from the differences in frequency and resistance at resonance for a loaded and a freely oscillating crystal. Usually only the fundamental frequency and its third overtone can be used.

McSkimmin reported on an alternative method using travelling torsional waves in a cylindrical rod (6). The waves are excited and detected by means of a torsional quartz crystal on top of the rod. At the bottom the rod is partly immersed in a liquid of which the properties are to be determined. This method offers a continuous frequency range and enables the measurements of viscoelastic data of electrically conducting liquids. Combining this geometry with a resonance method the frequency range can be extended at the lower side $(7,8,9)$.

Glover (10) introduced a thin-walled nickel tube as a carrier for travelling torsional waves. The waves are excited magnetostrictively. A pulse cancellation technique is used for detection. The sensitivity of an instrument based on a thin-walled tube is much larger than that of an instrument based on a rod of the same diameter. Moreover, corrections needed for the transition from characteristic cylindrical shear impedance to characteristic plane shear impedance are much smaller for a thin-walled tube than for a rod and may be neglected in most practical cases. Problems due to the use of the travelling wave method arise through undesired pulse reflections from the wet tube/dry tube boundary and from the damping device at the top of the tube. Problems inherent to the use of a nickel tube are encountered in maintaining a constant circular magnetization of the tube (11). The typical surface roughness of each tube requires careful cleaning and calibration of each tube.

Waterman et al. (12), further called: "ref. I", investigated the torsional resonance of a long nickel tube. The fundamental frequency was low: $3.7 \mathrm{kHz}$. Using many overtones an almost continuous frequency range can be established. With this method it is possible to realize excitation and detection of the torsional waves in two separate coils, which can be held at fixed positions during the measurements. As no position control of the coils is needed and the phase information of the detector signal is now unimportant, automatization and the use of standard electronic equipment is facilitated.
Recent developments of this method both theoretically and experimentally will be described in this paper.

\section{Theory}

An approximate solution for the torsional resonance of a tube immersed in liquid is given in ref. I. In this paper we shall expand the theory to allow for magnetostrictive excitation and detection of the torsional motion of a nickel tube.

In agreement with Yamamoto's theory (13) of the Wiedemann effect we will make two assumptions about the interactions of the transmitting and the receiving coil with a circumferentially magnetized nickel tube for very small values of the torsion in the tube:

A. An ideal transmitting coil causes a constant torsion moment in the tube over a length that equals the effective coil length $\alpha$ (see fig. 1). The magnitude of this torsion moment is proportional to the current through the transmitting coil. Hence

$M_{\mathrm{ext}}=\frac{C_{1} V_{\text {in }}}{i \omega L},-\alpha / 2<z<\alpha / 2$.

B. The longitudinal component of the magnetization $B_{\text {long }}$ is proportional to the torsion in the tube $\mathrm{\partial} \theta / \partial z$. Consequently

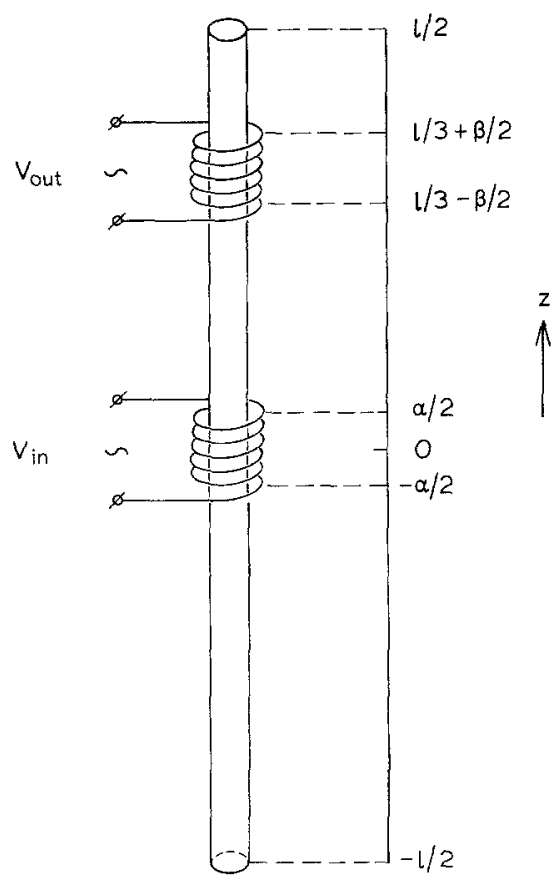

Fig. 1. Simplified geometry of the instrument 


$$
\begin{aligned}
V_{\text {out }} & =N \frac{\partial}{\partial t} \int_{\ell / 3}^{\ell / 3} B_{-\beta / 2}^{\beta / 2} B_{\text {long }} O d z \\
& =i \omega C_{2} \int_{\ell / 3-\beta / 2}^{\ell / 2} \frac{\partial \theta}{\partial z} d z .
\end{aligned}
$$

Experimental support for the latter assumption can be found in App. B.

For practical cases the torsional motion of the tube can be described as a rigid rotation of each cross section of the tube arounds its centre (ref. I). The equation of motion for a tube element $d z$ is now

$$
I \ddot{\theta}=\frac{\partial M_{\mathrm{el}}}{\partial z}+T_{\mathrm{liq}}+\frac{\partial M_{\mathrm{ext}}}{d z},
$$

where

$$
I=\frac{\pi}{2} \varrho_{\mathrm{Ni}} a^{4}\left(1-m^{4}\right)
$$

is the moment of inertia per unit length. The torsion moment due to elastic deformation of the tube equals

$M_{\mathrm{el}}=G_{\mathrm{Ni}} I_{p} \frac{\partial \theta}{\partial z}=\frac{G_{\mathrm{Ni}} I}{\varrho_{\mathrm{Ni}}} \frac{\partial \theta}{\partial z}$

and the moment per unit length, which the liquid exerts on the tube equals (ref. I)

$T_{\text {liq }}=2 \pi a^{3}\left(1+m^{3}\right) Z_{L} \dot{\theta}$.

With the exception of the transmitting coil boundaries, where $\frac{\partial M_{\mathrm{ext}}}{\partial z} \neq 0$, the problem reduces to that of ref. I, and [3] reduces to the wave equation for the complex torsion angle $\theta^{*}$ :

$$
\frac{\partial^{2} \theta^{*}}{\partial z^{2}}=\Gamma^{2} \theta^{*}
$$

with

$$
\Gamma^{2}=\frac{\varrho_{\mathrm{Ni}}}{G_{\mathrm{Ni}}}\left\{-\omega^{2}+i \omega Z_{L} A\right\}
$$

and apparatus constant

$$
A=\frac{4\left(1+m^{3}\right)}{\varrho_{\mathrm{Ni}} a\left(1-m^{4}\right)} \text {. }
$$

At the transmitting coil boundaries we require continuity of the total torsion moment in the tube:

$M_{\mathrm{tot}}=M_{\mathrm{el}}+M_{\mathrm{ext}}$.
As a consequence of [5] the slope of $\theta$ is therefore not continuous at the coil boundaries

$\lim _{z \downarrow \alpha / 2} \frac{\partial \theta}{\partial z}-\lim _{z \uparrow \alpha / 2} \frac{\partial \theta}{\partial z}=\frac{\varrho_{\mathrm{Ni}} M_{\mathrm{ext}}}{G_{\mathrm{Ni}} I}$,

$\lim _{z \downarrow-\alpha / 2} \frac{\partial \theta}{\partial z}-\lim _{z \uparrow-\alpha / 2} \frac{\partial \theta}{\partial z}=-\frac{\varrho_{\mathrm{Ni}} M_{\mathrm{ext}}}{G_{\mathrm{Ni}} I}$.

Neglecting liquid loading at the upper and lower cross sections of the tube,

$\left.\frac{\partial \theta}{\partial z}\right|_{z=\ell / 2}=\left.\frac{\partial \theta}{\partial z}\right|_{z=-\ell / 2}=0$,

and using the antisymmetry of the problem,

$\theta(0)=0$,

the following solution of [7] for $0<z<\ell / 2$ is obtained:

$\theta^{*}=\frac{\varrho_{\mathrm{Ni}} C_{1} V_{\mathrm{in}}}{i \omega L I G_{\mathrm{Ni}} \Gamma}\left\{\frac{\sinh \Gamma \alpha / 2 \sinh \Gamma z}{\cosh \Gamma \ell / 2}\right\}$, $0<z<\alpha / 2$,

$\theta^{*}=\frac{\varrho_{\mathrm{Ni}} C_{1} V_{\mathrm{in}}}{i \omega L I G_{\mathrm{Ni}} \Gamma}\left\{\frac{\sinh \Gamma \alpha / 2 \cosh \Gamma(\ell / 2-z)}{\cosh \Gamma \ell / 2}\right\}$,

$\alpha / 2<z<\ell / 2$.

The transfer function of the system "transmitting coil - nickel tube - receiving coil" is now calculated using [2]:

$$
\begin{aligned}
H= & \frac{V_{\text {out }}}{V_{\text {in }}}=\frac{2 \varrho_{\mathrm{Ni}} C_{1} C_{2}}{L I G_{\mathrm{Ni}} \Gamma} \\
& \cdot\left\{\sinh \frac{\Gamma \alpha / 2 \sinh \Gamma \beta / 2 \sinh \Gamma \ell / 6}{\cosh \Gamma \ell / 2}\right\} .
\end{aligned}
$$

If the system is only slightly damped the modulus of the transfer function can be approximated (see App. A) near those resonance frequencies, which give maximum torsion, i.e. nodal planes at the position of the receiving coil

$f_{n} \approx 3(2 n+1) \frac{c_{0}}{2 \ell}$.

The resulting working formulae are identical to those of ref. I,

$f_{n}^{A}-f_{n}=\frac{A X_{L}}{4 \pi}$ 
$B_{n}-B_{n}^{A}=\frac{A R_{L}}{2 \pi}$,

but they now apply to the modulus of the transfer function of the system which is actually measured. The above analysis therefore puts these working formulae on a more firm basis.

\section{Apparatus}

A prototype of the apparatus was described in detail in ref. I. We will therefore give only a short description and stress several improvements.

As has been pointed out by Rouse et al. (2) the support of a torsional resonator is essential for reproducibility. Since a tube has less inertia than a rod, the support of a nickel tube resonator is even more critical than that of a torsional crystal. In the prototype the clamping of the tube at the middle required a compromise between an undisturbed torsional motion and resistance against misalignement of the tube from the upright position. This suspension arrangement proved to be too critical for practical use.

The new design is shown schematically in fig. 2. A nickel tube with a length of $40 \mathrm{~cm}$, a diameter of 4 $\mathrm{mm}$ and a wall-thickness of $0.1-0.2 \mathrm{~mm}$, is hung between four stainless steel wires, $0.1 \mathrm{~mm}$ in diameter. The attachment has been achieved by making little knots in the wires behind four holes in the tube. These holes are $0.15 \mathrm{~mm}$ in diameter and bored in the tube at a distance of one sixth of the length of the tube from both ends. The nickel tube is surrounded by a glass tube containing the sample. Temperature stability of $0.01^{\circ} \mathrm{C}$ is established using a liquid thermostat bath.

The procedure to magnetize the tube circumferentially is only changed in so far, that the tube is now magnetized indirectly. To achieve this, an isolated copper wire is placed within the nickel tube for the conduction of three $1 \mathrm{~ms}, 500 \mathrm{~A}$ current pulses.

The transmitting coil applies an axial magnetic field to set the nickel tube in a torsional motion using the Wiedemann effect. The coil is positioned at the middle of the tube. The motion of the tube is monitored, using the inverse Wiedemann effect, in a second coil, the receiving coil, which is positioned near the attachment of the suspension wires at one sixth of the length of the tube. The design of both coils is unchanged.

The general arrangement is shown in fig. 3. A controllable HP $3330 \mathrm{~B}$ frequency synthesizer powers the transmitting coil. The signal from the receiving coil is amplified and filtered through an $1-300 \mathrm{kHz}$, $12 \mathrm{~dB} /$ octave bandfilter. A high precision HP $3490 \mathrm{~A}$ digital voltmeter, which replaces the tube voltmeter, transforms the AC signal into a standard ASCII code as input for a HP $9825 \mathrm{~A}$ desk calculator. This minicomputer controls all measurements, calculates the results and stores these on a cassette tape. The resonance parameters or viscoelastic data can be registered on plotter or printer.
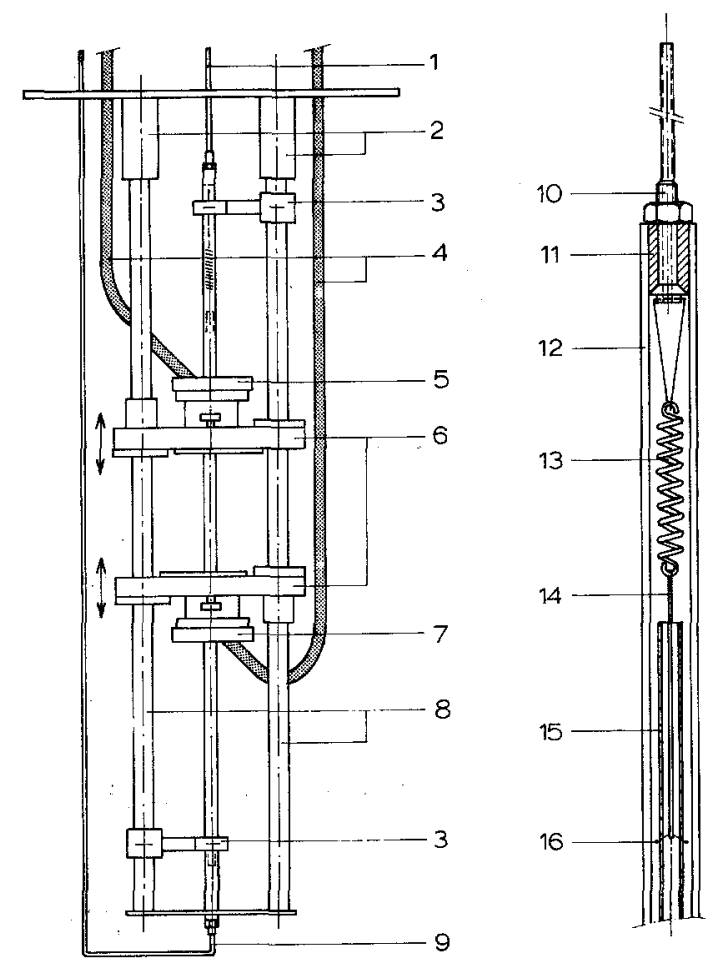

Fig. 2. Mechanical construction. 1 - stainless steel outlet capillary, 2 - thermal insulators, 3 - support of the glass tube, 4 - electrical lead, 5 - receiving coil, 6 - tunable coil supports, 7 - transmitting coil, 8 frame, 9 - stainless steel inlet capillary, 10 - screw thread enabling sealing, 11 - teflon seal, 12 glass tube, 13 - spring centering the nickel tube, 14 - suspension wires, 15 - nickel tube, 16 - knot 


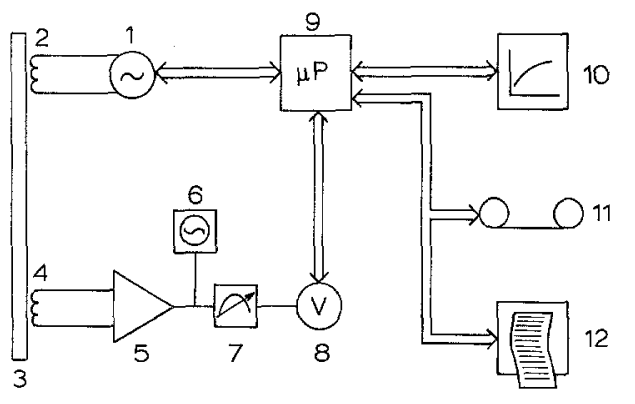

Fig. 3. General arrangement.

1 - controllable synthesizer, 2 - transmitting coil, 3 - nickel tube, 4 - receiving coil, 5 - amplifier, 6 oscilloscope, 7 - band filter, 8 - controllable voltmeter, 9 - minicomputer, 10 - plotter, 11 cassette recorder, 12 - printer

\section{Measurement procedure and data handling}

Before each measurement the tube must be thoroughly cleaned. It is flushed three times with ethanol absolute ${ }^{1}$ ) and three times with diethyl ether ${ }^{1}$ ). After each flushing the system is emptied and dried with compressed air. The air is dried in a Hankison refrigifilter, type F 50 .

Determination of the resonance frequency and bandwith of each resonance curve is performed in two steps. A coarse scanning of the transfer function of the system results in a first estimation for $B_{n}, f_{n}$ and the maximum of $|H|$ near resonance. More precise measurements are then performed using 11 measuring points per resonance curve with constant input voltage. These points are taken equidistant from $f_{n}-B_{n}$ to $f_{n}+B_{n}$. The constant input voltage is chosen so, that the output voltage at resonance, $\left|V_{\text {out }}\right|_{\max } \approx 0.75 \mathrm{mV}$ for each resonance curve.

Data handling of the resulting values of $\left|V_{\text {out }}\right|$ is carried out using the Nederveen transform (14). A least squares fit of $\zeta$ (see App. A) is made using the expression:

$\zeta=\left|\frac{2}{B_{n}}\left(f-f_{n}\right)+\frac{K}{B_{n} f_{n}}\left(f-f_{n}\right)^{2}\right|$.

1) Manufacturer: E. Merck, Darmstadt (B.R.D.).
$\left|V_{\text {out }}\right|_{\max }$ is determined iteratively by minimization of the least squares sum. The constant $K$ is a measure for deviations from ideal resonance behaviour.

Due to the use of the minicomputer it takes less than three minutes to perform the actual measurements and five minutes to execute the curve fittings for eight resonance curves. The application of a faster machine is not very profitable as cleaning procedures are more time consuming than the actual measurements.

\section{Calibration of the instrument}

The working formulae of the instrument are derived using the "no-slip" condition atsthe interface between a perfectly smooth tube surface and the sample. After a rigorous test Rouse et al. (2) concluded that [17] needs a correction due to liquid which is immobilized in the surface roughness of a resonator. A homogeneously distributed immobilized layer of liquid with average thickness $d_{\mathrm{eff}}$ contributes only to the inertia of the resonator and causes an additional decrease of the resonance frequencies of a resonator which is immersed in liquid.

$f_{n}^{A}-f_{n}=\frac{A X_{L}}{4 \pi}+A_{f}=\frac{A X_{L}}{4 \pi}+4 \pi A \varrho f d_{\mathrm{eff}}$.

Eqs. [18] and [20] have been verified experimentally for various Newtonian liquids. All liquids, except the bidestillated water, were "pro Analysi" grade commercial products. Eight overtones, ranging from 11 to $167 \mathrm{kHz}$, of two tubes, with wall-thickness of $0.2 \mathrm{~mm}$ (tube $\# A$ ) and $0.1 \mathrm{~mm}$ (tube $\# B$ ), were used. The apparatus constant $A$ was determined from eq. [18]. Values for $\eta$ and $\varrho$ were taken from (15). Detailed results for tube \#A are given in table 1.

The inertia correction $\Delta_{f}$ is simply

$\Delta_{f}=f_{n}^{A}-f_{n}^{N}-B_{n}^{N}+B_{n}^{A}$,

because for a Newtonian liquid $X_{L}=R_{L}=\sqrt{\pi f \eta \varrho}$.

A typical result for tube $\# A$ is given in table 2 . The validity of eq. [20] is made clear in figs. 4 and 5 .

For clarity of view not all data of table 2 are represented in fig. 5. Apparently all data can be summarized in the constant $A$ and $d_{\text {eff }}$. In table 3 this information is shown as well as theoretical estimations of $A$ from geometrical considerations for both tubes.

Table 1. Apparatus constant $A\left(\mathrm{~m}^{2} \mathrm{~kg}^{-1}\right)$ of tube $\# A$ as determined from eq. [18] for various Newtonian liquids at $42.1^{\circ} \mathrm{C}$

\begin{tabular}{lllllllll}
\hline sample & \multicolumn{7}{l}{ frequency $(\mathrm{kHz})$} \\
\cline { 2 - 9 } & 11 & 33 & 55 & 78 & 100 & 122 & 144 & 167 \\
\hline hexane & 0.0896 & 0.0893 & 0.0898 & 0.0905 & 0.0923 & 0.0912 & 0.0910 & 0.0922 \\
ethanol & 0.0920 & 0.0930 & 0.0931 & 0.0937 & 0.0943 & 0.0939 & 0.0937 & 0.0938 \\
cyclohexane & 0.0916 & 0.0917 & 0.0923 & 0.0926 & 0.0926 & 0.0922 & 0.0919 & 0.0925 \\
water & 0.0917 & 0.0928 & 0.0931 & 0.0935 & 0.0938 & 0.0938 & 0.0940 & 0.0940 \\
chloroform & 0.0900 & 0.0894 & 0.0898 & 0.0903 & 0.0906 & 0.0909 & 0.0911 & 0.0912 \\
\hline
\end{tabular}




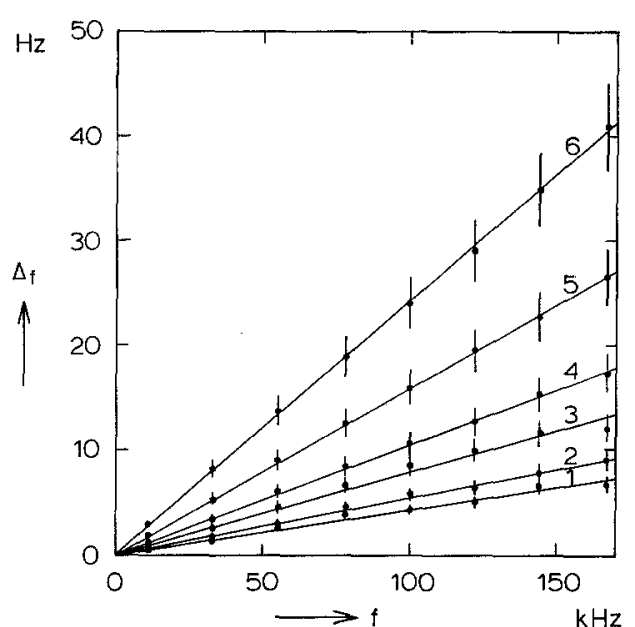

Fig. 4. Correction term $\Delta_{f}$ as a function of frequency. 1 - hexane, 2 - ethanol, 3 - water, 4 chloroform, 5 - 1,2-dibromoethane, 6 - diiodomethane

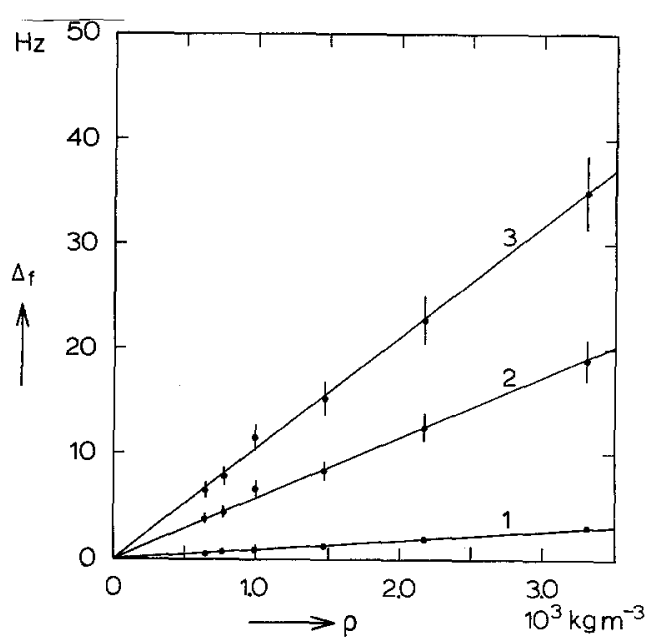

Fig. 5. Correction term $\Delta_{f}$ as a function of liquid density: 1) at $11 \mathrm{kHz} ; 2$ ) at $78 \mathrm{kHz}$; 3) at $144 \mathrm{kHz}$

Table 2. Inertia correction term $\Delta_{f}(\mathrm{~Hz})$ of tube $\# A$ as determined from eq. [21] for various Newtonian liquids at $42.1^{\circ} \mathrm{C}$

\begin{tabular}{|c|c|c|c|c|c|c|c|c|}
\hline \multirow[t]{2}{*}{ sample } & \multicolumn{8}{|c|}{ frequency $(\mathrm{kHz})$} \\
\hline & 11 & 33 & 55 & 78 & 100 & 122 & 144 & 167 \\
\hline hexane & 0.49 & 1.4 & 2.6 & 3.8 & 4.3 & 5.0 & 6.5 & 6.7 \\
\hline ethanol & 0.65 & 1.8 & 3.0 & 4.5 & 5.7 & 6.4 & 7.8 & 9.0 \\
\hline water & 0.87 & 2.6 & 4.5 & 6.6 & 8.5 & 10.0 & 11.6 & 12.1 \\
\hline chloroform & 1.2 & 3.5 & 6.0 & 8.4 & 10.6 & 12.7 & 15.3 & 17 \\
\hline 1,2 dibromoethane & 1.9 & 5.3 & 9.0 & 12.5 & 16 & 20 & 23 & 27 \\
\hline diiodomethane & 3.0 & 8.3 & 13.7 & 19 & 24 & 29 & 35 & 41 \\
\hline
\end{tabular}

Table 3. Apparatus constants

\begin{tabular}{lllrl}
\hline tube & $\begin{array}{l}\text { wall- } \\
\text { thickness } \\
(\mathrm{mm})\end{array}$ & $\begin{array}{l}A_{\text {geom. }} \\
\left(10^{-3}\right. \\
\left.\mathrm{m}^{2} \mathrm{~kg}^{-1}\right)\end{array}$ & $\begin{array}{l}A_{\text {exp }} \\
\left(10^{-3}\right. \\
\left.\mathrm{m}^{2} \mathrm{~kg}^{-1}\right)\end{array}$ & $\begin{array}{l}d_{\text {eff }} \\
\left(10^{-2}\right. \\
\mu \mathrm{m})\end{array}$ \\
\hline$A$ & 0.2 & $94 \pm 2$ & $92 \pm 2$ & $13 \pm 2$ \\
$B$ & 0.1 & $188 \pm 4$ & $186 \pm 3$ & $11 \pm 4$ \\
\hline
\end{tabular}

The accuracy of the measurements is affected by uncertainties in $A$ and $d_{\text {eff }}$. Since the tube geometry is not homogeneous these uncertainties may include systematic errors. Errors are also caused by demagnetization of the nickel tube. This phenomenon is most probably responsible for the observed increase in resonance frequency with time. To achieve the utmost accuracy in the measurements on viscoelastic samples, the properties of each sample are compared with those of a Newtonian calibration liquid with the same density. Thus $A, \Delta_{f}$ and $f_{n}^{A}$ can be eliminated from [18] and [20] and the formulae

$X_{L} / R_{L}^{N}=\left[2\left(f_{n}^{N}-f_{n}\right)+B_{n}^{N}-B_{n}^{A}\right] /\left(B_{n}^{N}-B_{n}^{A}\right)[22]$ and,

$R_{L} / R_{L}^{N}=\left(B_{n}-B_{n}^{A}\right) /\left(B_{n}^{N}-B_{n}^{A}\right)$

can now be used to calculate the properties of a viscoelastic sample.

\section{Measurements on a viscoelastic fluid}

As an example we performed measurements on a solution of polystyrene in dibutyl phthalate at $12.13^{\circ} \mathrm{C}$. Data on the composition of this solution are given below ${ }^{2}$ ). Steady-state viscosity $(80.15 \mathrm{mPa} \mathrm{s})$ and solvent viscosity $\left(\eta_{s}=\right.$ $30.31 \mathrm{mPa} \mathrm{s}$ ) were obtained from Ubbelohde

2) The polystyrene used in this investigation was delivered by Pressure Chemical Co., Pittsburg and had, according to the manufacturer, the following properties: $\bar{M}_{w}=400.000$ and $\bar{M}_{w} / \bar{M}_{n}=1.06$. Dibutyl phthalate, purity $>99 \%$, was obtained from J. Baker Chemical Co., Phillipsburg. The concentration of the solution used was $14.1 \mathrm{mg} / \mathrm{ml}$. 


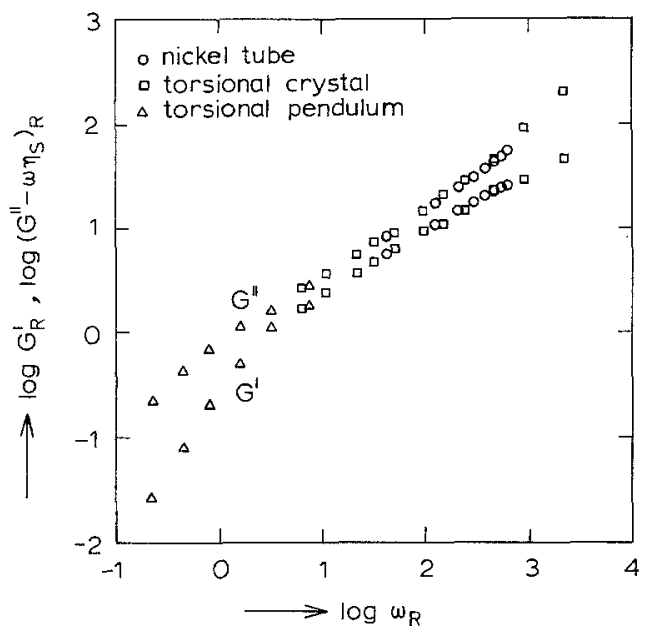

Fig. 6. Reduced shear moduli of solutions of polystyrene in toluene as a function of the reduced frequency

measurements. Measurements on a solution of the same polymer in the same solvent were performed in our laboratory with the aid of a torsional crystal and a torsional pendulum apparatus at various temperatures. In order to compare these results with each other the reduced data (16) are given in fig. 6.

\section{Discussion}

The instrument is simple, accurate and sensitive. The use of the magnetostrictive effect allows measurements of electrically conducting liquids. Measurements can be carried out quickly and easily as a result of automatization. As a consequence of the speed of the measurement the calibration procedure cancels out systematic errors caused by demagnetization of the nickel tube. It is therefore now possible to use a tube for months without the need for remagnetization.

The overall accuracy of the measurements of viscoelastic data is estimated from results obtained from different Newtonian samples, having (almost) the same density but different viscosities. It was concluded that the following empirical rules apply for the relative errors in the measurements of $G^{\prime}$ and $G^{\prime \prime}$ :

$\varepsilon_{G^{\prime \prime}} \approx 0.5-2 \%, \quad \frac{G^{\prime}}{G^{\prime \prime}} \varepsilon_{G^{\prime}} \approx 0.5-2 \%$.

The lower values for these errors are applicable if the extrapolations are small, i.e. if the sample viscosity and the viscosity of the calibration liquid are almost equal.

In table 4 this instrument is compared with its most advanced competitors. A drawback of this instrument turns out to be the limited frequency range. Experiments with a thicker tube, having a wall-thickness of $0.4 \mathrm{~mm}$, to diminish the influence of the suspension wires might expand the frequency range at the lower side to include the fundamental frequency. At the higher side the frequency range of the apparatus is limited by the resonance frequency of the receiving coil.

Table 4. Comparison of different instruments

\begin{tabular}{|c|c|c|c|c|c|}
\hline author & Sakanishi (5) & Ookubo (9) & $\begin{array}{l}\text { Nakajima } \\
(7,8)\end{array}$ & Glover (10) & this paper \\
\hline drive & $\begin{array}{l}\text { piezo-elec- } \\
\text { trical }\end{array}$ & $\begin{array}{l}\text { piezo-elec- } \\
\text { trical }\end{array}$ & $\begin{array}{l}\text { piezo-elec- } \\
\text { trical }\end{array}$ & $\begin{array}{l}\text { magneto- } \\
\text { strictive }\end{array}$ & $\begin{array}{l}\text { magneto- } \\
\text { strictive }\end{array}$ \\
\hline method & resonance & resonance & $\begin{array}{l}\text { travelling } \\
\text { wave }\end{array}$ & $\begin{array}{l}\text { travelling } \\
\text { wave }\end{array}$ & resonance \\
\hline geometry & crystal & $\begin{array}{l}\text { crystal }+ \\
\text { rod }\end{array}$ & $\begin{array}{l}\text { crystal }+ \\
\text { rod }\end{array}$ & tube & tube \\
\hline frequency range $(\mathrm{kHz})$ & $20-120$ & $2-525$ & $30-500$ & $20-200$ & $11-170$ \\
\hline number of measuring points & & 6 & not discrete & not discrete & \\
\hline viscosity range ( $\mathrm{mPa}$ s) & $<1000$ & $\geqslant 1$ & $\geqslant 1$ & $\geqslant 1$ & $0.1-10$ \\
\hline error in $G^{\prime \prime}$ at $30 \mathrm{kHz}$ & $1 \%$ & $1 \%$ & $1 \%$ & $2 \%$ & $0.5-2 \%$ \\
\hline max. rate of shear & - & - & - & $1 \mathrm{~s}^{-1}$ & $\left.30-100 \mathrm{~s}^{-13}\right)$ \\
\hline required amount of sample $(\mathrm{ml})$ & 10 & 2 & 10 & 10 & \\
\hline $\begin{array}{l}\text { time needed for measuring and } \\
\text { data treatment }\end{array}$ & $?$ & ? & ? & $?$ & $8 \min$ \\
\hline
\end{tabular}


Preliminary results using an improved coil indicate that the method is useful for measurements up to $300 \mathrm{kHz}$.

\section{Appendix A: Relations between the characteristic shear impedance of the liquid surrounding the tube and the modulus of the transfer function near resonance}

If the coil lengths $\alpha$ and $\beta$ are small with respect to the wavelength of the motion in the tube [15] reduces to:

$H=C \Gamma \frac{\sinh \Gamma \ell / 6}{\cosh \Gamma \ell / 2}$.

If $C \Gamma$ is constant ${ }^{4}$ ) within the frequency range of interest (from $f_{n}-B_{n}$ to $f_{n}+B_{n}$ ), it is sufficient to consider the function:

$F=\frac{\sinh \Gamma \ell / 6}{\cosh \Gamma \ell / 2}$.

Small damping of the system means that:

$\left|A Z_{L}\right| \ll 1$

and

$\operatorname{tg} \delta \ll 1$.

Under these conditions it follows from [8]:

$$
\begin{aligned}
\Gamma & \approx \sqrt{\frac{\varrho_{\mathrm{Ni}}}{G_{\mathrm{Ni}}^{\prime}}}\left\{i \omega+\frac{A Z_{L}}{2}+\frac{\omega G_{\mathrm{Ni}}^{\prime \prime}}{2 G_{\mathrm{Ni}}^{\prime}}\right\} \\
& =\frac{1}{c_{0}}\left\{i \omega+\frac{A Z_{L}}{2}+\frac{\omega \operatorname{tg} \delta}{2}\right\} .
\end{aligned}
$$

Defining

$\frac{\Gamma \ell}{6} \equiv X+i Y$

the modulus of $F$ becomes

$|F|=\sqrt{\frac{\cosh 2 X-\cos 2 Y}{\cosh 6 X+\cos 6 Y}}$

where

$X=\frac{\ell}{6 c_{0}}\left\{\frac{A R_{L}}{2}+\frac{\omega \operatorname{tg} \delta}{2}\right\}$

and

$Y=\frac{\ell}{6 c_{0}}\left\{\omega+\frac{A X_{L}}{2}\right\}$.

${ }^{4}$ ) It can be shown that, if $C \Gamma$ is approximated by a linear function of the frequency in the above frequency range, an analogous derivation results in the same working formulae [17] and [18].
The resonance condition for a free-free tube without losses in vacuum is

$\omega_{0}=\frac{c_{0}}{\ell} k \pi, \quad k=1,2,3 \ldots$.

In this case $X=0$ and the solution for $\theta$ corresponds with the standing wave pattern

$\theta=\hat{\theta} \sin (k \pi / \ell) z$.

In our case only those resonance peaks that have nodal planes at the positions of the suspension wires, $z= \pm \ell / 3$, are applicable

$k=3(2 n+1), \quad n=0,1,2 \ldots$.

In a practical case, with damping, we will consider a first order Taylor expansion of [A7] about

$Y_{0}=\frac{\ell \omega_{0}}{6 c_{0}}=(2 n+1) \frac{\pi}{2}$.

Substitution of $Z=Y-Y_{0}$ into [A7] yields

$|F|=\sqrt{\frac{\cosh 2 X+\cos 2 Z}{\cosh 6 X-\cos 6 Z}}$.

[A14]

Since

$\frac{\partial X}{\partial \omega} \approx \frac{\ell}{6 c_{0}}\left\{\frac{-A R_{L}}{4 \omega}+\frac{\operatorname{tg} \delta}{2}\right\} \ll \frac{\ell}{6 c_{0}} \approx \frac{(2 n+1) \pi}{2 \omega}$

and

$$
\begin{aligned}
\frac{\partial Z}{\partial \omega} & \approx \frac{\partial Y}{\partial \omega} \approx \frac{\ell}{6 c_{0}}\left\{1-\frac{A X_{L}}{4 \omega}\right\} \\
& \approx \frac{l}{6 c_{0}} \approx \frac{(2 n+1) \pi}{2 \omega}
\end{aligned}
$$

the variation of $X$ may be neglected and variations of $Z$ are linear in $\omega$ for small variations of $\omega$ around $\omega_{0}$. Thus amplitude resonance for the tube with loss terms is found for $Z=0$ i.e. for

$\omega_{n}+A X_{L} / 2=3(2 n+1) \pi$.

For a lumped oscillator the graph of the parameter

$\zeta=\sqrt{\left[\frac{|F|_{\max }}{|F|}\right]^{2}-1}$

against $\left|\omega-\omega_{n}\right|$ should show a straight line through the origin (14). The slope of this line is proportional to the inverse of the bandwith of the system. From [A14] and [A19] it is found that

$$
\begin{aligned}
\zeta & =\left\{\frac{(\cosh 6 X-\cos 6 Z)(\cosh 2 X+1)}{(\cosh 2 X+\cos 2 Z)(\cosh 6 X-1)}-1\right\}^{1 / 2} \\
& \approx 3 Z \sqrt{\frac{2}{\cosh 6 X-1}} .
\end{aligned}
$$

For a slightly damped system it finally follows from [A3], [A4], and [A20] that 
$\frac{B_{n}}{2}=\left|\frac{\partial \zeta}{\partial f}\right|^{-1}=\frac{3 c_{0} X}{\pi \ell}=\frac{1}{4 \pi}\left(A R_{L}+\omega \operatorname{tg} \delta\right)$.

The working formulae [17] and [18] are readily obtained from [A18] and [A21].

\section{Appendix B: Determination of the maximum rate of shear in the sample during measurements}

In order to calculate the maximum rate of shear in the sample it is necessary to quantify the relation [2] between the output voltage of the receiving coil and the torsion of the tube. At the lower resonance frequencies the length of the receiving coil is very small with respect to the wavelength of the torsional motion of the tube. Using approximation [A11] we find

$\left|V_{\text {out }}\right|_{\max }=\frac{\omega^{2} C_{2} \hat{\theta}}{c_{0} \beta}=C_{3} k^{2} \hat{\theta}$.

The maximum torsion angle of the tube was determined optically using the simple configuration of fig. 7. A laser beam was reflected by a mirror, dimensions $10 \times 0.4 \mathrm{~mm}$, that was ground on the tube surface at the top of the tube. The reflected beam was projected on a transparent screen at a distance $b$ from the tube. The magnitude $p$ of the track on the screen was determined with the aid of a Polaroid camera when the tube was in motion and at rest. It is easily verified that

$$
\hat{\theta}=\frac{p-p_{\text {rest }}}{4 b} \text {. }
$$

Results for the lower three resonance frequencies are shown in fig. 8. From the slope of the graph it is learned that $C_{3}=(12 \pm 1) V^{-1}$.

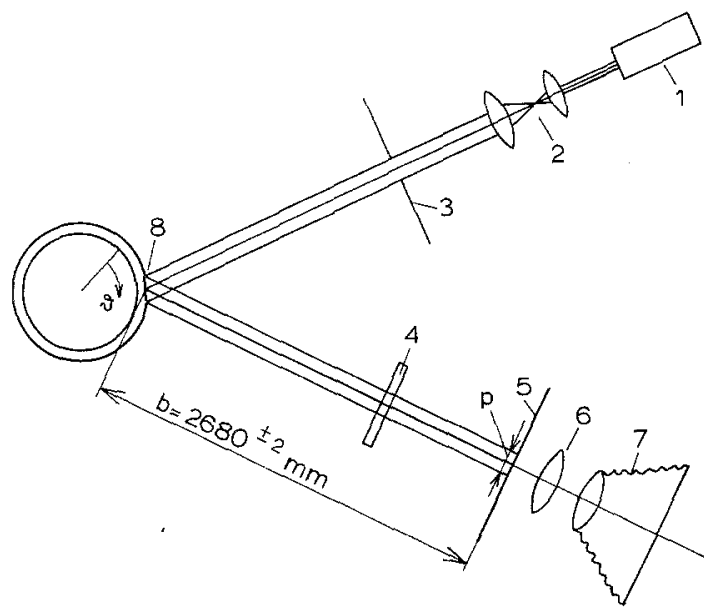

Fig. 7. Optical arrangement for the measurement of the maximum torsion angle of the tube.

1 - laser, 2 - beam expander, 3 - slit, 4 cylindrical lens for convergence in plane perpendicular to figure, 5 - transparent screen, 6 correction lens, 7 - camera, 8 - mirror ground on the tube surface

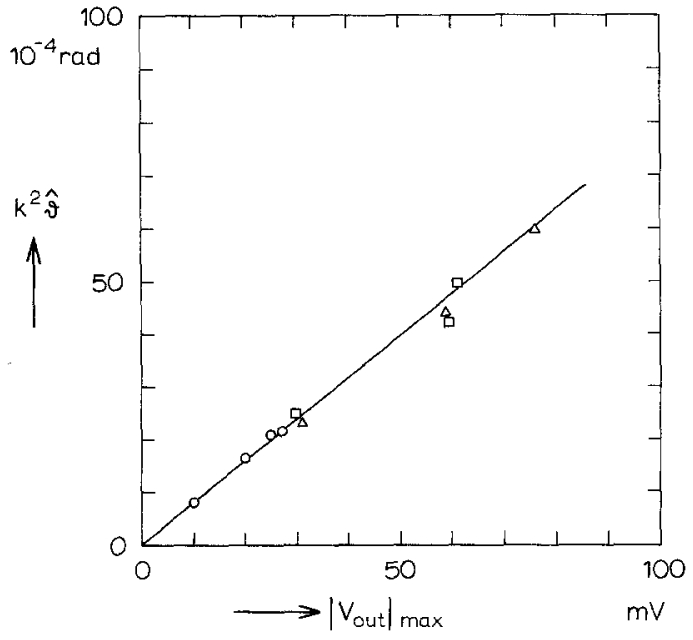

Fig. 8. Relation between the maximum torsion angle $\hat{\theta}$ and the output voltage of the receiving coil

For the Newtonian liquid the maximum rate of shear is

$\dot{\gamma}_{\max }=\omega a \sqrt{\frac{\omega \varrho}{\eta}} \hat{\theta}=\frac{a \omega_{1}^{2}}{C_{3}} \sqrt{\frac{\varrho}{\omega \eta}}\left|V_{\text {out }}\right|_{\max }$.

In a typical experimental situation, for instance water at $100 \mathrm{kHz}$ with $\left|V_{\text {out }}\right|_{\max } \approx 0.75 \mathrm{mV}$, it is found that $\dot{\gamma}_{\max } \approx 80 \mathrm{~s}^{-1}$.

\section{Summary}

An apparatus for the measurement of liquid-shear impedance in the frequency range $11-170 \mathrm{kHz}$ using a thin-walled nickel-tube resonator is described. The working principle of the method used has been previously published. Compared with the prototype the most important advances in the design concern the suspension of the resonator and complete automatization of the measurements and data handling. At the cost of not measuring at the fundamental frequency accuracy and ease of operation are greatly improved. Results for Newtonian and viscoelastic liquids are presented. Comparison with other types of apparatus is made.

\section{Zusammenfassung}

Es wird über einen Apparat zur Messung der Scherimpedanz von Flüssigkeiten im Frequenzbereich von 11 bis $170 \mathrm{kHz}$ berichtet, bei dem ein Nickelrohr mit geringer Wandstärke als Resonator verwendet wird. Das Arbeitsprinzip dieses Apparats wurde schon früher veröffentlicht. Im Vergleich mit dem Prototyp betreffen die wichtigsten Verbesserungen die Aufhängung des Resonators und die völlige Automatisierung der Messungen und der Datenverarbeitung. Die Genauigkeit und die Bequemlichkeit der Handhabung sind erheblich vergrößert, allerdings werden die Messungen jetzt nicht mehr bei der Grundfrequenz durchgeführt. Es werden Ergebnisse für newtonsche 
und viskoelastische Flüssigkeiten mitgeteilt und ein Vergleich mit anderen Apparaten durchgeführt.

\section{References}

1) Mason, W. P., Trans A.S.M.E. 69, 359 (1947).

2) Rouse jr., P. E., E. D. Bailey, J. A. Minkin, Proc. A.P.I. $30 \mathrm{M}, 54$ (1950).

3) Barlow, A. J., G. Harrison, J. Richter, H. Seguin, J. Lamb, Lab. Pract. 10, 786 (1961).

4) Appeldoorn, J. K., E. H. Okrent, W. Philippoff, Proc. A.P.I. 42 III, 1963 (1962).

5) Sakanishi, A., H. Tanaka, Jap. J. Appl. Phys. 12, 1410 (1973).

6) McSkimmin, H. J., J. Acoust. Soc. Amer. 24, 355 (1952). (1970).

7) Nakajima, H., Y. Wada, Polymer J. 1, 727

8) Nakajima, H., H. Okamoto, Y. Wada, Polymer J. 5, 268 (1973).

9) Ookubo, N., M. Komatsubara, H. Nakajima, Y. Wada, Biopolymers 15, 929 (1976).

10) Glover, G. M., G. Hall, A. J. Matheson, J. L. Stretton, J. Phys. E 1, 383 (1968), G. M. Glover, G.
Hall, A. J. Matheson, J. L. Stretton, Proc. 5th Int. Congr. Rheol. 1, 429 (1969).

11) Cooke, B. J., A. J. Matheson, J. Chem. Soc. 72, 679 (1976).

12) Waterman, H. A., M. Oosterbroek, G. J. Beukema, E. G. Altena, Rheol. Acta 18, 585 (1979).

13) Yamamoto, M., J. Appl. Phys. Japan 27, 88 (1958), J. Phys. Soc. Japan 12, 981 (1972).

14) Nederveen, $C . J$. , Internal report $\mathrm{CL} 68 / 42$ T.N.O., Delft.

15) Weast, R. C., "Handbook of chemistry and physics" (55th ed.), C.R.C. Press (Cleveland, Ohio 1974).

16) Ferry, J. D., "Viscoelastic properties of polymers", Chap. 9, John Wiley \& Sons (New York 1969).

Authors' address:

$M$. Oosterbroek et al.

Department of Applied Physics

Twente University of Technology

7500 AE Enschede (The Netherlands) 